\title{
Prevention of early infective complications after laparoscopic splenectomy with the Garamycin sponge
}

\author{
Marcin Migaczewski, Anna Zub-Pokrowiecka, Piotr Budzyński, Maciej Matłok, Andrzej Budzyński \\ $2^{\text {nd }}$ Department of General Surgery, Medical College Jagiellonian University, Krakow, Poland
}

Videosurgery and Other Miniinvasive Techniques 2012; 7 (2): 105-110 DOI: 10.5114/wiitm.2011.27151

\begin{abstract}
Introduction: Surgical site infection (SSI) appear to be more frequent in splenectomized patients than might be expected and its incidence can be explained neither by the extent of surgery nor by the risk of bacterial contamination of the operating field.

Aim: Evaluation the local antibiotic prophylaxis using a gentamicin surgical implant in order to reduce SSI, particularly subphrenic abscesses.

Material and methods: We conducted a prospective, randomized study of two groups of patients undergoing laparoscopic splenectomy who were considered at high risk of infective complications: patients with idiopathic thrombocytopenic purpura (ITP) pre-treated chronically with systemic steroids and patients with non-Hodgkin lymphoma (NHL). Out of 98 laparoscopic splenectomies performed during the study period, 40 patients with ITP and 20 with NHL met the inclusion criteria and were enrolled in the study. In 20 randomly selected patients with ITP and 10 with NHL, a gentamicin-collagen implant was left in the splenic bed.

Results: Infective complications occurred in 4 (6.67\%) among 60 patients from the entire study group; 2 in patients with ITP and a gentamicin implant who developed fever of unknown cause which resolved after systemic antibiotics, and 2 in patients with NHL and gentamicin prophylaxis who developed a subphrenic abscess. In all patients operated on without a gentamicin implant, the postoperative course was uncomplicated.

Conclusions: Gentamicin surgical implants not only fail to reduce the risk of subphrenic abscesses in splenectomized patients, but may contribute to the increase in its incidence, which puts into question the possible benefits of this form of prophylaxis.
\end{abstract}

Key words: laparoscopic splenectomy, infective complications, gentamicin implant.

\section{Introduction}

The spleen is one of the most crucial elements of the human immune system, but its function has not been fully recognized [1]. At first, it was believed that its removal did not entail any significant implications. Only later observations of long-term infective complications after splenectomy, such as fulminating sepsis referred to as overwhelming post-splenectomy infection (OPSI) revealed the risk. Because of them, it is currently known that spleen removal causes significant impairment of the immune mechanisms [2, 3]. Early postoperative, local, infective complications constitute a somewhat less known problem. It has been observed that in patients after splenectomy the surgical site becomes infected (surgical site infections - SSI) much more often than could be expected. Especially, abscesses occur frequently at the site of the removed spleen. Its incidence can be explained 
neither by the range of the procedure nor by the risk of surgical field infection. The considerable risk of abscess occurrence in the splenic site causes preventive actions. Perioperative systemic antibiotic prophylaxis does not ensure complete protection [4]. Research on local use of antibacterial drugs has been undertaken in order to prevent infections in the splenic site. In the literature concerning the issue no reports of studies of such kind were found.

\section{Aim}

The aim of the study was to determine whether antibiotic prophylaxis with a Garamycin sponge left at the splenic site influences the risk of local infective complications.

\section{Material and methods}

A prospective, randomized study was carried out in 2 groups of patients with increased risk of infective complications. Both of them had undergone laparoscopic splenectomy. Patients with idiopathic thrombocytopenic purpura (ITP) and non-Hodgkin lymphoma (NHL) were eligible for the study.

In case of ITP the inclusion criteria were: diagnosis based on the clinical picture, bone marrow biopsy and the demonstration of antiplatelet antibody, platelet count at the level of 50 000-100 000 in the immediate preoperative period, normal-sized spleen, and minimum 3-month steroid therapy continued to the time of the procedure.

Patients who: were treated for ITP with other than steroidal methods such as immunoglobulins or immunosuppression, had extreme thrombocytopenia, presented with active bacterial infection, had positive history of other diseases influencing the resistance, had splenomegaly and/or hypersplenism diagnosed, required conversion to an open procedure, and patients with intraoperative iatrogenic gastric perforation were excluded from the study.

In the case of patients with NHL the inclusion criteria were: confirmed diagnosis of splenic variety of diffuse large B-cell lymphoma (DLBCL) or mantle cell lymphoma $(\mathrm{MCL})$, previous systemic treatment (chemotherapy).

Patients with: active bacterial infection, positive history of other diseases influencing the resistance, determined thrombocytopenia, intraoperative iatro- genic gastric perforation and patients converted to an open procedure were excluded from the study.

In all the patients routine prophylaxis of infective complications after splenectomy was carried out. It included vaccination and prophylactic antibiotics (ceftriaxonum $2 \mathrm{~g}$ per day - the medicine accepted by the Hospital Infection Control Committee for perioperative prophylaxis). Pneumococcal vaccine polyvalent was administered about 4 weeks before the scheduled procedure. A similar scheme was employed in case of Haemophilus influenzae type B among patients who had not been vaccinated during childhood. The antibiotic was routinely administered $1 \mathrm{~h}$ before the procedure and continued on the $1^{\text {st }}$ postoperative day. All the patients were operated on by the same surgical team. The procedure was performed with the patient in a right lateral position, with 4 trocars placed along the left costal arch. The aortic trunk and splenic vein were clipped. The splenic hilum was dissected with the Ligasure $^{\circledR}$ device without isolating separate vessel branches. The excised spleen was placed in a plastic bag and after fragmentation removed bit by bit through a slightly widened trocar wound. Closed gravity $16 \mathrm{~F}$ drains were employed at the splenic site. They were left until the amount of drained fluid was less than $50 \mathrm{~cm}^{3}$ per day. Patients with both ITP and NHL were randomized into 2 groups. In half of them a Garamycin sponge was used $-G(+)$, in others it was not G (-).

Local infective complications occurrence was assessed until 30 days after the procedure.

From September 2007 to December 2009, laparoscopic splenectomy was indicated for different reasons in 98 cases. Out of them 40 patients with ITP and 20 with NHL met the inclusion criteria. Twenty patients with ITP and 10 with NHL were randomized to receive a Garamycin sponge during laparoscopy. Demographic data of the patients enrolled in the study did not differ significantly between groups (Table I).

In the group treated without a Garamycin implant, $G(-)$, the average size of the spleen in the initial ultrasound was $15.2 \mathrm{~cm}$ (range: $9-30 \mathrm{~cm}$ ), in the group with ITP it was $11.3 \mathrm{~cm}$ (range: $9-13 \mathrm{~cm}$ ) and in the series with lymphoma it was $22.5 \mathrm{~cm}$ (range: $14-30 \mathrm{~cm})$. In the group treated with a Garamycin sponge, $G(+)$, the average length of the spleen was $14.8 \mathrm{~cm}$ (range: $10-25 \mathrm{~cm}$ ). In the series with ITP it was $12.8 \mathrm{~cm}$ (range: $10-14 \mathrm{~cm}$ ) and with NHL it was $17 \mathrm{~cm}$ 
Table I. Demographic data of the patients operated on

\begin{tabular}{|c|c|c|c|c|c|c|c|c|c|c|}
\hline \multirow[t]{2}{*}{ Group } & & \multicolumn{2}{|c|}{$N$} & \multicolumn{2}{|c|}{ Sex } & \multicolumn{4}{|c|}{ Age [years] } & \multirow[t]{2}{*}{ Value of $p$} \\
\hline & & & & $F$ & $M$ & Average & $S D$ & Min & Max & \\
\hline \multirow[t]{2}{*}{ G (-) } & ITP & 30 & 20 & 14 & 6 & 39.2 & 14.2 & 20 & 60 & \multirow[t]{4}{*}{ NS } \\
\hline & $\mathrm{NHL}$ & & 10 & 4 & 6 & 55.3 & 15.2 & 26 & 78 & \\
\hline \multirow[t]{2}{*}{ G (+) } & $I T P+G$ & 30 & 20 & 13 & 7 & 41.6 & 19.8 & 18 & 75 & \\
\hline & $\mathrm{NHL}+\mathrm{G}$ & & 10 & 4 & 6 & 56.4 & 7.1 & 49 & 71 & \\
\hline
\end{tabular}

G (-) - no Garamycin was used, G (+) - Garamycin was used, ITP - patients with idiopathic thrombocytopenic purpura who did not receive Garamycin, NHL patients with non-Hodgkin lymphoma who did not receive Garamycin, ITP $+G$ - patients with idiopathic thrombocytopenic purpura who received Garamycin, $\mathrm{NHL}+\mathrm{G}$ - patients with non-Hodgkin lymphoma who received Garamycin

(range: $14-25 \mathrm{~cm}$ ). The differences between the groups were not statistically significant (Table II).

In the whole group of patients with ITP and with $\mathrm{NHL}$, who did not receive Garamycin implant treatment, $G(-)$, the average time of the procedure was 94.7 min (range: 35-140 min) and average intraoperative blood loss was assessed at $119 \mathrm{~cm}^{3}$ (range: $\left.0-500 \mathrm{~cm}^{3}\right)$. The most substantial intraoperative bleeding $\left(500 \mathrm{~cm}^{3}\right)$ occurred in the case of a pathologically obese patient (body mass index $-\mathrm{BMI}-38 \mathrm{~kg} / \mathrm{m}^{2}$ ). However, in no case was there any need to transfuse blood components and derivatives. Median postoperative drainage in this group was $30.3 \mathrm{~cm}^{3}$ (range: $0-180 \mathrm{~cm}^{3}$ ). In the group of patients with Garamycin implant treatment, $\mathrm{G}(+)$, median time of the procedure was $80.1 \mathrm{~min}$ (range: 35-160 $\mathrm{min}$ ), and blood loss was assessed at $52.8 \mathrm{~cm}^{3}$ (range: $0-300 \mathrm{~cm}^{3}$ ) - Table III. Average postoperative drainage was $48.6 \mathrm{~cm}^{3}$ of bloody contents (range: $0-280 \mathrm{~cm}^{3}$ ). The most substantial amount was observed in the case of a 71-year-old patient with a delayed response to splenectomy and postoperative thrombocytopenia. Intraoperative blood loss in this case was $250 \mathrm{~cm}^{3}$.
Table II. Size of the spleen in the USG in particular groups

\begin{tabular}{|c|c|c|c|c|c|c|}
\hline \multirow[t]{2}{*}{ Group } & & \multirow[t]{2}{*}{$n$} & \multicolumn{3}{|c|}{ Spleen size $[\mathrm{cm}]$} & \multirow[t]{2}{*}{ Value of $p$} \\
\hline & & & \multicolumn{2}{|c|}{ Average } & Range & \\
\hline \multirow[t]{2}{*}{$G(-)$} & ITP & 20 & 15.2 & 11.3 & $9-13$ & NS \\
\hline & $\mathrm{NHL}$ & 10 & & 22.5 & $14-30$ & \\
\hline \multirow[t]{2}{*}{$\mathrm{G}(+)$} & $\mathrm{ITP}+\mathrm{G}$ & 20 & 14.8 & 12.8 & $10-14$ & \\
\hline & $\mathrm{NHL}+\mathrm{G}$ & 10 & & 17 & $14-25$ & \\
\hline
\end{tabular}

Abbreviations - see Table I

\section{Results}

No systemic complications other than infective or death cases were observed. Out of 60 patients operated on, 4 (6.67\%) presented with an infection (Table IV). All the cases were observed in the group with a Garamycin sponge used, G (+) - Table IV. In 2 patients it was a local infection, in 1 patient from the ITP $+\mathrm{G}$ group it was $39^{\circ} \mathrm{C}$ fever of unknown origin lasting for 2 postoperative days. It remitted after empiric antibiotic therapy. In another patient with ITP

Table III. Time of the procedure, blood loss and drainage in particular groups

\begin{tabular}{|c|c|c|c|c|c|c|c|c|c|c|c|}
\hline \multicolumn{2}{|c|}{ Group } & \multirow{3}{*}{$\begin{array}{l}n \\
20\end{array}$} & \multicolumn{3}{|c|}{ Time of procedure [min] } & \multicolumn{3}{|c|}{ Blood loss $\left[\mathrm{cm}^{3}\right]$} & \multicolumn{3}{|c|}{ Drainage $\left[\mathrm{cm}^{3}\right]$} \\
\hline & & & \multicolumn{2}{|c|}{ Median } & \multirow{2}{*}{$\begin{array}{l}\text { Range } \\
35-120\end{array}$} & \multicolumn{2}{|c|}{ Median } & \multirow{2}{*}{$\begin{array}{l}\text { Range } \\
0-500\end{array}$} & \multicolumn{2}{|c|}{ Median } & \multirow{2}{*}{$\begin{array}{l}\text { Range } \\
0-100\end{array}$} \\
\hline $\mathrm{G}(-)$ & ITP & & 94.7 & 75 & & 118.8 & 75.3 & & 30.3 & 27 & \\
\hline & $\mathrm{NHL}$ & 10 & & 95 & $70-140$ & & 99 & $10-300$ & & 41 & $0-180$ \\
\hline \multirow[t]{2}{*}{$\mathrm{G}(+)$} & $\mathrm{ITP}+\mathrm{G}$ & 20 & 80.1 & 80 & $35-110$ & 52.8 & 60 & $0-300$ & 48.6 & 54 & $0-280$ \\
\hline & $\mathrm{NHL}+\mathrm{G}$ & 10 & & 80 & $50-160$ & & 38 & 10-100 & & 37 & $0-130$ \\
\hline
\end{tabular}

Abbreviations - see Table I 
Table IV. Immediate infective complications in particular groups

\begin{tabular}{|c|c|c|c|c|c|}
\hline \multicolumn{2}{|c|}{ Group } & \multicolumn{2}{|c|}{$n$} & \multicolumn{2}{|c|}{ Infective complications } \\
\hline \multirow[t]{2}{*}{$G(-)$} & ITP & 30 & 20 & 0 & 0 \\
\hline & $\mathrm{NHL}$ & & 10 & & 0 \\
\hline \multirow[t]{2}{*}{$\mathrm{G}(+)$} & $\mathrm{ITP}+\mathrm{G}$ & 30 & 20 & 4 & $2^{*}$ \\
\hline & $\mathrm{NHL}+\mathrm{G}$ & & 10 & & $2^{* *}$ \\
\hline
\end{tabular}

${ }^{*}$ Clinical symptoms of an infection of unknown origin, ${ }^{* *}$ local infective complications (abscesses at the splenic site)

$($ ITP $+\mathrm{G})$ on the $7^{\text {th }}$ postoperative day fever $\left(\right.$ about $\left.38^{\circ} \mathrm{C}\right)$ occurred. Ultrasound revealed the possibility of fluid collection at the splenic site. After intravenous administration of amoxycillin, the symptoms disappeared and ultrasonography (USG) did not confirm subphrenic abscess. In both cases blood culture was negative. In 2 patients with splenic variety of $\mathrm{NHL}$, who received Garamycin sponge treatment ( $\mathrm{NHL}+\mathrm{G}$ group), clinical symptoms of intra-abdominal abscess were observed. In both cases, they were patients with mantle cell lymphoma. One of them was a 62-year-old patient who had an abscess at the splenic site and splenic vein thrombosis diagnosed on the $8^{\text {th }}$ postoperative day. Laparoscopic re-surgery was performed. The Garamycin implant was found in the abscess wall. The presence of a hospital strain of Pseudomonas aeruginosa was determined in the contents collected for bacteriological testing. The patient was re-operated on 3 weeks after the $2^{\text {nd }}$ procedure - the presence of abscess was determined intraoperatively. In the second patient from the $\mathrm{NHL}+\mathrm{G}$ group, a 51-year-old man, fluid collection at the splenic site sized $10 \mathrm{~cm} \times 3 \mathrm{~cm}$ was demonstrated by computed tomography (CT). Successful drainage through a pigtail caterer placed with USG guidance was performed. A negative culture was collected after 72-h incubation from the sample, which macroscopically looked like puss. Blood culture was also negative in both patients.

\section{Discussion}

Despite complicated pre-surgical preparation schemes including vaccination and antibiotics, infective complications are one of the most significant issues in patients after splenectomy. Late septic complications after the removal of the spleen, OPSI being a model example, do not exhaust the topic. There is, however, a whole group of infective complications occurring in the early postoperative period, which is rarely found in reports. Immediate infective complications after splenectomy are connected with bacterial flora typical of the alimentary tract, originating from bacterial or hospital translocation. Long-term infective complications after splenectomy are mostly invoked by pneumococcus and meningococcus and other bacteria with lipopolysaccharide outer membrane [4]. It is worth emphasizing that early and late infective post-splenectomy complications are two completely different issues. They differ with respect to their spectrum of pathogens responsible for the occurrence and mechanisms underlying their aetiopathogenesis [4]. The question arises concerning prevention of early complications. The statement that splenectomy itself, regardless of its type, the way it is performed and the level of postoperative infection, is an indication for antibiotic prophylaxis should not raise major objections. Its common use should be reconsidered in patients with chronic steroid therapy, positive history of additional ailments and previous chemotherapy. Antibiotic prophylaxis, assortment of medicines, and the length of time they are used in the case of abdominal, surgical procedures have been quite precisely stipulated. What is interesting, the majority of those stipulations do not include splenectomy as an indication for its use [5-14]. There are a number of reports whose authors recommend long-term antibiotic therapy in patients after splenectomy in order to prevent late infective complications. Some authors suggest antibiotic prophylaxis prior to the scheduled splenectomy. Legrand reports that the French Committee of Experts recommends preoperative antibiotic prophylaxis in patients undergoing splenectomy [15]. Also Mozillo states that in $60 \%$ of Italian hospitals splenectomy is an indication for antibiotic prophylaxis, despite the fact that the procedure is classified as class I of surgical field contamination (clean) [16]. Stopiński also recommends similar treatment [17]. His opinion is based on the observed increased risk of post-splenectomy wound infection. Before antibiotic prophylaxis was introduced, wound suppuration occurred in $8.15 \%$ of patients, afterwards in 3.57\% [17]. On the other hand, clinical observations reveal limited success of systemic antibiotics in the prevention of subphrenic abscesses occurrence in post-splenectomy patients $[16,18]$. Looking for other solutions, we decided to make an attempt at the method used in cardio- 
surgery in order to prevent bone and marrow inflammation after sternotomy. Both splenectomy and the majority of heart surgeries are classified as "clean" procedures. However, the incidence of SSI is surprisingly high. The Local Gentamicin Infection Prophylaxis (LOGIP) study performed in a series of 2000 patients operated on by cardiosurgeons through the sternotomy access revealed a $53 \%$ decrease (9\% vs. $4.3 \%)$ of sternum infection incidence after a gentamicin implant was used besides standard antibiotic prophylaxis [19]. Eklund and Schersten presented similar results in their reports [20-22]. In his studies concerning infected site prophylaxis (SSI), Praven showed similar effectiveness of systemic antibiotics in comparison to local gentamicin application in patients having undergone inguinal hernioplasty [23]. Rutten's work revealed a significant (5.6\% vs. 18.4\%) decrease of postoperative wound infections after combined therapy of Garamycin sponge and systemic antibiotics in patients undergoing elective large bowel surgery [24]. The instanced results impelled us to try to employ the Garamycin sponge in order to prevent infection at the splenic site, especially as we have not found similar studies in the literature. Surprisingly, and against expectations, local antibiotic prophylaxis did not diminish the risk of local infection after splenectomy, but both cases of subphrenic abscesses occurred in the series of patients with the sponge left. In the series without local antibiotic therapy, no infective complications were observed within 30 postoperative days. A highly statistically significant disparity between groups was observed. Among others, the occurrence of resistant bacterial strains in response to the longterm liberation of the antibiotic may be a possible explanation for the ensuing situation. The fact that strains of hospital type ( $P$. aeruginosa) were cultured from the abscess appears to confirm the theory. Some authors believe that drains left are responsible for the subsequent development of infections at the splenic site. Identical postoperative drainage in all patients does not explain the difference between the analysed groups. As both analysed groups were relatively numerically small, it does not allow unequivocal conclusions to be drawn. At the same time, the observed complications made us terminate the project. The obtained results show that the Garamycin sponge left at the splenic site does not diminish the risk of subphrenic abscesses, but may be predestined to such complications. The obtained results put into question the benefits of such treatment.

\section{References}

1. Ramachandra J, Bond A, Ranaboldo C, Cullis J. An audit of postsplenectomy prophylaxis: are we following the guidelines? Ann R Coll Surg Engl 2003; 85: 252-5.

2. Coignard-Biehler $\mathrm{H}$, Lanternier F, de Montalembert $\mathrm{M}$, et al. Infections in splenectomized patient. Rev Prat 2008; 58: 2209-14.

3. Hasse B, Moll C, Oehy K, et al. Anti-infectious prophylaxis after splenectomy: current practice in an eastern region of Switzerland. Swiss Med Wkly 2005; 135: 291-6.

4. Budzyński A. Ryzyko infekcji po usunięciu śledziony, źródła hemocyty, polipeptydów o działaniu bakteriobójczym. Rozprawa habilitacyjna. Wydawnictwo Medycyna Praktyczna, Kraków 2007.

5. Altemeier WA. Manual of control of infections in surgical patients. American College of Surgeons Press, Chicago 1976.

6. Barie PS. Modern surgical antibiotic prophylaxis and therapyless is more. Surg Infect 2000; 1: 23-9.

7. Beytout J, Tournilhac O, Laurichesse H. Antibiotic prophylaxis in splenectomized adults. Presse Medicale, Paris 2003; 32: S17-9.

8. Mangram AJ. A brief overview of the 1999 CDC Guideline for the Prevention of Surgical Site Infection. Centers for Disease Control and Prevention. J Chemother 2001; 13 Spec 1: 35-9.

9. Nichols RL, Condon RE, Barie PS. Antibiotic prophylaxis in surgery: 2005 and beyond. Surg Infect 2005; 6: 349-61.

10. Solomkin JS, Mazuski JE, Baron EJ, et al.; Infectious Diseases Society of America. Guidelines for the selection of anti-infective agents for complicated intra-abdominal infections. Clin Infect Dis 2003; 37: 997-1005.

11. Stone HH, Bourneuf AA, Stinson LD. Reliability of criteria for predicting persistent or recurrent sepsis. Arch Surg 1985; 120: 17-20.

12. Legrand A, Bignon A, Borel $M$, et al. Perioperative management of asplenic patients. Ann Fr Anesth Reanim 2005; 24: 807-13.

13. Bednarek M, Budzyński P, Budzyński A, Demczuk S. Sarcoidosis of the spleen - rare indications for splenectomy. Own experience. Videosurgery and Other Miniinvasive Techniques 2010; 5: $115-9$.

14. Dzielicki J, Grabowski A, Korlacki W. Optimizing the technique of laparoscopic splenectomy in children. Videosurgery and Other Miniinvasive Techniques 2010; 5: 19-26.

15. Michalik M, Bobowicz M, Lech P, Orłowski M. Distal pancreatic resection via laparo-endoscopic single site surgery - development of the technique. Videosurgery and Other Miniinvasive Techniques 2010; 5: 142-5.

16. Mozzillo N, Greco D, Pescini A, Formato A. Chemoprophylaxis in the surgical ward: results of a national survey in Italy. Eur J Epidemiol 1988; 4: 357-9.

17. Stopinski J, Staib I, Jaeschke C. Splenectomy-a strictly aseptic intervention? Langenbecks Arch Chir 1994; 379: 233-6.

18. Koratzanis G, Giamarellos-Bourboulis EJ, Papalambros E, Giamarellou H. Bacterial translocation following intrabdominal surgery. Any influence of antimicrobial prophylaxis? Int I Antimicrobial Agents 2002; 20: 457-60. 
19. Friberg O. Local collagen-gentamicin for prevention of sternal wound infections: the LOGIP trial. APMIS 2007; 115: 1016-21.

20. Eklund AM, Valtonen M, Werkkala KA. Prophylaxis of sternal wound infections with gentamicin-collagen implant: randomized controlled study in cardiac surgery. J Hosp Infect 2005; 59: 108-12.

21. Eklund AM. Prevention of sternal wound infections with locally administered gentamicin. APMIS 2007; 115: 1022-4.

22. Schersten H. Modified prophylaxis for preventing deep sternal wound infection after cardiac surgery. APMIS 2007; 115: 1025-8.

23. Praveen S, Rohaizak M. Local antibiotics are equivalent to intravenous antibiotics in the prevention of superficial wound infection in inguinal hernioplasty. Asian J Surg 2009; 32: 59-63.

24. Rutten HJ, Nijhuis PH. Prevention of wound infection in elective colorectal surgery by local application of a gentamicin-containing collagen sponge. Eur J Surg Suppl 1997; 578: 31-5. 